Goldschmidt 2021 Abstract

https://doi.org/10.7185/gold2021.4598

\section{Systematic enrichment of mantle harzburgites: new insights from San Carlos xenoliths}

\author{
ROMAIN TILHAC ${ }^{1,2}$, TOMOAKI MORISHITA ${ }^{3}$, AKIHIRO \\ TAMURA $^{3}$ AND JUAN MIGUEL GUOTANA ${ }^{3}$ \\ ${ }^{1}$ Instituto Andaluz de Ciencias de la Tierra (IACT/CSIC) \\ ${ }^{2}$ Macquarie University \\ ${ }^{3}$ Kanazawa University
}

Presenting Author: romain.tilhac@csic.es

Since pioneering works on San Carlos peridotites (e.g. [1]), the dichotomy between partial melting and metasomatism has evolved into a paradigm of mantle geochemistry. The occurrence of LREE-enriched harzburgites has indeed been widely, and perhaps conveniently, ascribed to these discrete magmatic processes. Yet, the thermo-chemical implications of such multistage interpretations are often poorly considered, and they mostly fail to account for the fact that trace-element enrichment and major-element depletion are often proportional. We here report new data on San Carlos peridotites calling for a reconsideration of a paradigm at odds with the current understanding of the mantle's magmatic processes. Our results show that, compared to the lherzolites' homogeneous fertility, the harzburgites are discriminated by low-Jd and high-Jd clinopyroxene characterized by marked zoning, with low-Mg\# and Na-Al-Cr-rich rims. We interpret these features as a variability induced by local elemental redistribution in the presence of a low-degree hydrous melt, which probably also led to the wide range of LREE enrichment and MREE-to-HREE fractionation observed.

To confirm this interpretation, we ran open-system melting simulations of hydrous flux melting (Fig. 1), which show that such trace-element fractionation is indeed consistent with low fluid influx producing poorly extracted melt (as in the high-Jd samples), while higher influx leads to more efficient melt extraction (as in low-Jd). The lithological and chemical heterogeneity of San Carlos mantle is thus compatible with a single-stage evolution associated with the development of melt extraction pathways, promoted by reactive channeling instability during hydrous flux melting. This interpretation is further supported by the striking consistency of our Fe-Mg and REE thermometric estimates, indicating that lherzolites and harzburgites followed a single P-T path and experienced little sub-solidus re-equilibration. We believe that such process is frequent in the lithospheric mantle, providing a self-consistent explanation for many occurrences of LREE-depleted lherzolites and LREE-enriched harzburgites. In the local context of San Carlos, we argue that it probably occurred in a $1.5-\mathrm{Ga}$ continental lithosphere affected by the recent tectonic reactivation of a Proterozoic subduction zone (Fig. 2), which provides further constraints on the volcanic sources of the Jemez Lineament.

[1] Frey \& Prinz (1978), EPSL 38, 129-176.
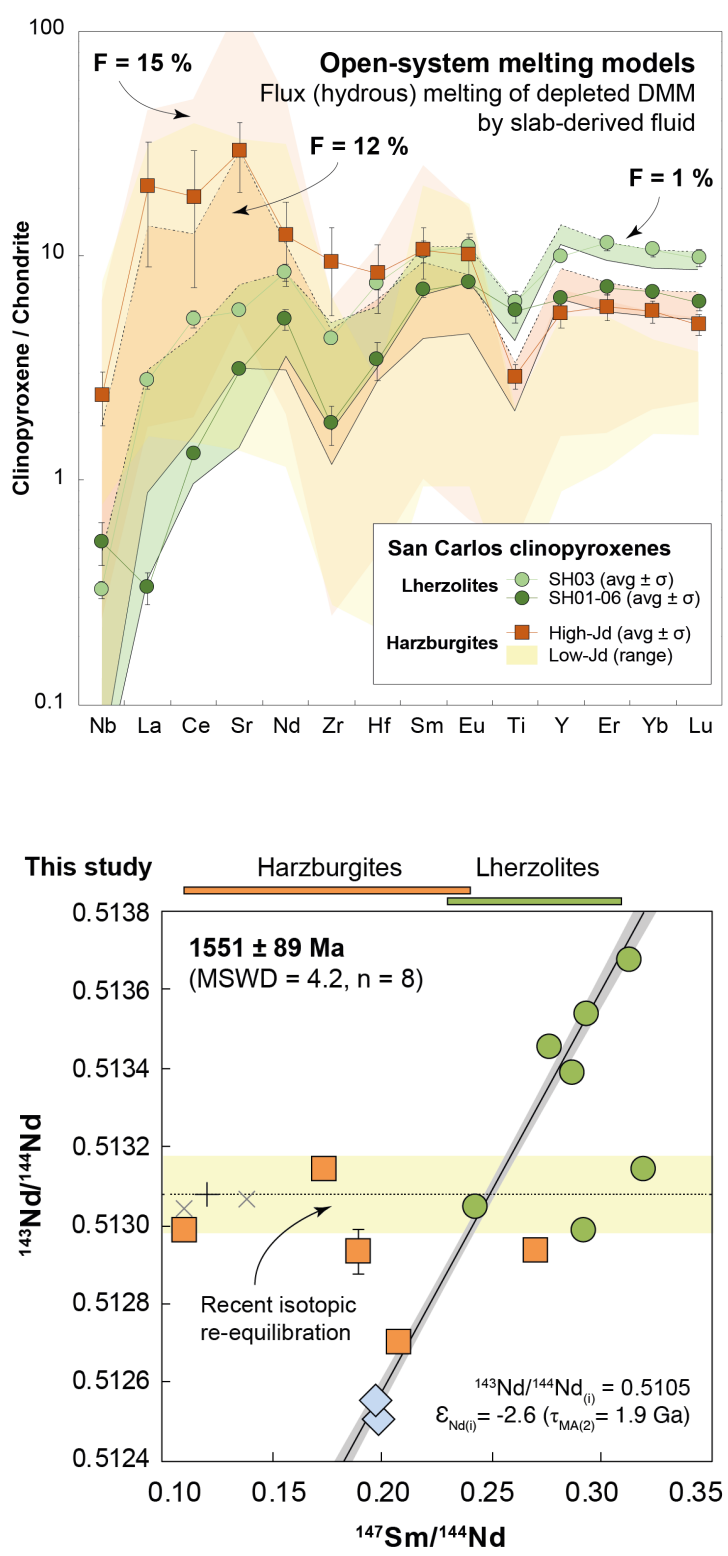